\title{
Temporal trends in the use of targeted temperature management after cardiac arrest and association with outcome: insights from the Paris Sudden Death Expertise Centre
}

Jean-Baptiste Lascarrou ${ }^{1,2,3,4^{*}}$ (1), Florence Dumas ${ }^{2,3,5}$, Wulfran Bougouin ${ }^{2,3,4}$, Richard Chocron ${ }^{2,3,5}$, Frankie Beganton ${ }^{2,3}$, Stephane Legriel $\left.\right|^{2,3,4,6}$, Nadia Aissaoui ${ }^{2,3,4,7}$, Nicolas Deye ${ }^{2,3,4,8}$, Lionel Lamhaut 2,3,4,9, Daniel Jost ${ }^{2,10}$, Antoine Vieillard-Baron ${ }^{2,11}$, Eloi Marijon ${ }^{2,3}$, Xavier Jouven ${ }^{2,3}$, Alain Cariou ${ }^{2,3,4,12}$ and on behalf of the SDEC

\begin{abstract}
Purpose: Recent doubts regarding the efficacy may have resulted in a loss of interest for targeted temperature management (TTM) in comatose cardiac arrest (CA) patients, with uncertain consequences on outcome. We aimed to identify a change in TTM use and to assess the relationship between this change and neurological outcome.

Methods: We used Utstein data prospectively collected in the Sudden Death Expertise Center (SDEC) registry (capturing CA data from all secondary and tertiary hospitals located in the Great Paris area, France) between May 2011 and December 2017. All cases of non-traumatic OHCA patients with stable return of spontaneous circulation (ROSC) were included. After adjustment for potential confounders, we assessed the relationship between changes over time in the use of TTM and neurological recovery at discharge using the Cerebral Performance Categories (CPC) scale.
\end{abstract}

Results: Between May 2011 and December 2017, 3925 patients were retained in the analysis, of whom 1847 (47\%) received TTM. The rate of good neurological outcome at discharge (CPC 1 or 2) was higher in TTM patients as compared with no TTM (33\% vs 15\%, $P<0.001)$. Gender, age, and location of CA did not change over the years. Bystander CPR increased from 55\% in 2011 to $73 \%$ in $2017(P<0.001)$ and patients with a no-flow time longer than 3 min decreased from 53 to 38\% ( $P<0.001)$. The use of TTM decreased from 55\% in 2011 to 37\% in $2017(P<$ 0.001). Meanwhile, the rate of patients with good neurological recovery remained stable (19 to $23 \%, P=0.76$ ). After adjustment, year of CA occurrence was not associated with outcome.

Conclusions: We report a progressive decrease in the use of TTM in post-cardiac arrest patients over the recent years. During this period, neurological outcome remained stable, despite an increase in bystander-initiated resuscitation and a decrease in "no flow" duration.

Keywords: Cardiac arrest, Induced hypothermia, Targeted temperature management, Neurological outcome

\footnotetext{
* Correspondence: jeanbaptiste.lascarrou@chu-nantes.fr

'Service de Medecine Intensive Reanimation, Centre Hospitalier Universitaire,

30 Boulevard Jean Monnet, 44093 Nantes Cedex 9, France

2Université de Paris, INSERM, Paris Cardiovascular Research Centre, Paris,

France

Full list of author information is available at the end of the article
}

(c) The Author(s). 2019 Open Access This article is distributed under the terms of the Creative Commons Attribution 4.0 International License (http://creativecommons.org/licenses/by/4.0/), which permits unrestricted use, distribution, and reproduction in any medium, provided you give appropriate credit to the original author(s) and the source, provide a link to the Creative Commons license, and indicate if changes were made. The Creative Commons Public Domain Dedication waiver (http://creativecommons.org/publicdomain/zero/1.0/) applies to the data made available in this article, unless otherwise stated. 


\section{Introduction}

Over the last decades, implementation of the "chain of survival" led to a progressive improvement in outcome after cardiac arrest (CA) in many places across the world [1]. In addition to pre-hospital management, postcardiac arrest care is now considered as a major determinant of outcome. Among the interventions that can be provided during the post-resuscitation period, recent data raised some concerns regarding the benefit of targeted temperature management (TTM) for comatose CA survivors. Even if TTM is strongly recommended in out-of-hospital CA provoked by a ventricular arrhythmia, its effectiveness has been seriously challenged in several other situations, such as in nonshockable [2] and in-hospital CA patients [3]. Additionally, the TTM trial that showed no difference between 33 and $36^{\circ}$ may have been falsely considered by some clinicians as a negative study regarding the effectiveness of TTM [4]. On the whole, this may have resulted in a change in TTM modalities in post-cardiac patients, as reported by several investigators [5]. In a recent survey, Deye et al. observed that $37 \%$ of responders changed their attitude regarding TTM over the recent years, many of them moving from $33^{\circ} \mathrm{C}$ toward a higher temperature level [6].

Possible consequences of these changes on patients' outcome are unclear. After moving from a TTM target of 33 to $36^{\circ} \mathrm{C}$, Bray et al. reported low compliance with target temperature, higher rates of fever, and a trend toward clinical worsening in patient outcomes [7]. In a recent retrospective study performed in Australia and New Zealand, similar changes in clinicians' attitude regarding target temperature after $\mathrm{CA}$, which occurred in up to one third of ICU, were associated with an increased proportion of patients with fever [5]. In the USA, where this treatment was historically less employed as compared with European countries, TTM use was shown to further decrease in many centers, as revealed by recent administrative data [8]. In parallel, Khera et al. found that TTM use dropped in all subgroups of CA survivors (both shockable and non-shockable) [9]. On the whole, these uncertainties prompted to perform new large randomized trials testing this treatment in CA patients. The recently released HYPERION study showed an improvement in long-term neurological prognosis with TTM at $33^{\circ}$ as compared to normothermia for CA patients with non-shockable rhythm [10], and the TTM2 trial comparing TTM at $33^{\circ}$ versus fever control is actually ongoing.

We hypothesized that a change in French clinicians' attitude regarding TTM may have occurred in the period that preceded these new trials and that this change may have affected the outcome in post-CA patients. In order to explore this hypothesis, we decided to perform an in-depth analysis of a regional registry covering the Great Paris area (France).

\section{Materials and methods Study design}

We used data extracted from the cardiac arrest registry managed by the Sudden Death Expertise Center (SDEC) of the Great Paris area (France), which was previously described [11]. Our aim was to search for a change in the use of TTM over the recent years and to assess the relationship between this change and the patient's outcome after adjustment for potential confounders.

\section{Study setting}

In Paris and its surrounding suburbs (Haut-de-Seine, Seine-Saint-Denis, Val-de-Marne), the management of OHCA involves mobile emergency units and fire departments, covering $762 \mathrm{~km}^{2}$ and a population of 6.6 million inhabitants. The Emergency Medical Service is a twotiered physician-manned system, with a basic life support (BLS) tier served by firefighters of the Brigade de Sapeurs-Pompiers de Paris, who can apply automated external defibrillators, and an advanced cardiac life support (ACLS) tier, provided in the field, with endotracheal intubation, intravenous access line, and drugs if necessary. Resuscitation is delivered by an emergency team that includes at least one trained physician in emergency medicine and one nurse, applying international guidelines. Patients with stable return of spontaneous circulation (ROSC) are then transferred to a secondary or tertiary center with an intensive care unit (ICU) and coronary intervention facilities with a target of door to balloon of $120 \mathrm{~min}$ maximum for acute coronary syndrome with ST elevation on ECG.

From 2011, all OHCA cases occurring in Paris and its suburbs are recorded in a prospective population-based registry system managed by the Paris Sudden Death Expertise Center (Paris-SDEC) [12, 13].

\section{Study population}

According to recent guidelines [14], all cases of OHCA (defined as unexpected death without obvious extracardiac cause, such as drowning, trauma, hanging, intoxication) are prospectively recorded in the Paris-SDEC registry according to Utstein style. In the present analysis, we retained all post-cardiac arrest patients transported to the hospital and admitted in ICU with a sustainable ROSC from May 15, 2011, to December 31, 2017. Exclusion criteria were age below 18 years, prior terminal condition (e.g., metastatic malignancy), obvious non-cardiac cause according to Utstein templates [14], patients who died before hospital admission, and refractory OHCA transported to the hospital for potential extra-corporal life support (ECLS). 


\section{Data collection}

The following variables are collected in the registry: age, gender, location, witnessed status, bystander cardiopulmonary resuscitation, initial cardiac rhythm, cumulative epinephrine dose employed during resuscitation, delays from collapse to start of chest compressions (no flow) and from start of chest compression to ROSC (low flow), characteristics of the post-resuscitation ECG, arterial $\mathrm{pH}$ at hospital admission, temperature management, and coronary interventions after hospital admission.

The neurological outcome was scored using the level reached on the Cerebral Performance Categories (CPC) scale [15] at ICU discharge, assessed by the physician in charge. Patients with a good cerebral performance (CPC1) or a moderate cerebral disability (CPC2) were considered to have a favorable neurological recovery.

\section{Patients' management}

TTM was considered as the provision of any measure aiming to reduce the patient's body temperature by either non-invasive or by invasive means. According to current guidelines, the targeted temperature was comprised between 32 and $36^{\circ} \mathrm{C}$ [16]. TTM could be started in the emergency department or in the ICU according to each center policy.

Early invasive coronary strategy was defined as a coronary angiography (followed by percutaneous coronary intervention if indicated) performed in the very first hours following hospital admission. Post-resuscitation shock was defined as the occurrence or persistence of arterial hypotension (mean arterial pressure $<60 \mathrm{mmHg}$ or systolic blood pressure $<90 \mathrm{mmHg}$ ) sustained for more than $6 \mathrm{~h}$ after ROSC despite adequate fluid resuscitation and requiring a continuous infusion of vasopressor.

Definitions and modalities for data collection were unchanged during the period of the study. Data were entered prospectively into a study database and checked for completeness and accuracy. Two investigators (FD, $\mathrm{AC}$ ) reviewed each record for data completion and validity.

\section{Statistical analysis}

We used descriptive statistics to summarize categorical variables as proportions, and continuous variables as mean with standard deviation for normal distribution or as median with interquartile range for non-normal distribution. Comparisons between proportions used Pearson's chi-squared (or Fisher's exact test if appropriate) and $t$ test for continuous variables (or Mann-Wilcoxon rank-sum test).

According to the different analyses, we used three different options regarding the "year of cardiac arrest," which was analyzed as a continuous or a categorical variable, or divided into four a priori defined periods $(\mathrm{P})$ based on the publication of the TTM trial [3]: P1 was the baseline period (year 2011); P2 was the period before the publication of the TTM trial (years 2012 and 2013); P3 was the period that immediately followed the publication of the TTM trial (year 2014), and P4 being the most recent period (years 2015, 2016, and 2017).

We first assessed the relationship between baseline characteristics and the use of TTM. Test for trend and logistic regression were used to evaluate the pattern of neurological recovery over time and the potential explicative factors.

We then performed a univariate analysis testing the different parameters associated with good neurological recovery at ICU discharge. Association between TTM and outcome was analyzed in a multivariate model adjusted on Utstein variables including age, gender, location of arrest, provision of bystander CPR, resuscitation intervals, initial rhythm, epinephrine use, arterial $\mathrm{pH}$ at admission, occurrence of a post-cardiac arrest shock, early coronary angiogram performance, TTM, and year of arrest as continuous. In order to take into account missing data, we performed multiple imputations using chained equation [17] on the dataset restricted to patients with available survival status at hospital discharge (primary outcome), based on $\mathrm{M}=10$ imputed completed datasets.

In a sensitivity analysis aiming to assess the influence of prognostic factors over time, we included in the primary multivariate model an interaction (cross-product) term between year and covariates of interest (initial rhythm, bystander CPR performance, TTM).

Focusing on the role of TTM, we also evaluated the potential for generalized temporal trends to account for the study period association by using segmented regression analysis of interrupted time series data using time categorized in four a priori sub-periods (P1, P2, P3, and P4). This method allows to assess how much an intervention changed an outcome of interest, immediately and over time [18].

All tests were two-sided with a $P$ value considered significant if $<0.05$. Analyses were performed using STAT A/SE 14.2 (Lakeway Drive, TX, USA).

\section{Results}

During the study period, 25,059 patients were included in the Paris-SDEC registry. Cardiopulmonary resuscitation was not attempted in 7923 patients, an obvious non-cardiac cause of arrest was evidenced in 3782 patients, resuscitation failed in 8766 patients (who were not transported according to French EMS policy), and 663 patients with refractory CA were transported without ROSC to the hospital for potential extra-corporeal life support. This left 3925/25059 (16\%) patients suitable 
for the present analysis, of whom 1847/3925 (47\%) received TTM (see Additional file 1). Numbers of missing data are displayed on Additional file 2.

Patients' characteristics according to temperature management are displayed in Table 1. As compared with controls, those who received TTM were more frequently men and younger; cardiac arrest occurred more frequently in a public place, and the proportion of patients with a long no-flow duration (higher than $3 \mathrm{~min}$ ) was greater $(P<0.001)$. An early invasive coronary strategy was used more frequently in TTM patients $(P<0.001)$. As compared with controls, those who received TTM had more frequently a good neurological recovery at ICU discharge $(15 \%$ vs $33 \%, P<0.001)$.

Changes over the years in patients' characteristics and management appear in Table 2. Gender, age, and location of CA did not significantly change over time. Bystander CPR increased from $55 \%$ in 2011 to $73 \%$ of patients in $2017(P<0.001)$, no-flow time upper than 3 min decreased from 53 to $38 \%(P<0.001)$ (Table 2$)$. During the study period, the overall proportion of patients receiving TTM decreased from 55\% in 2011 to $37 \%$ in $2017(P<0.001)$. This decrease in TTM use over years was observed in both shockable and non-shockable patients (see Fig. 1). Using segmented regression separating the study period into four separate sub-periods $(\mathrm{P} 1=2011, \quad \mathrm{P} 2=2012-2013, \mathrm{P} 3=2014, \mathrm{P} 4=2015-17)$, the decrease in TTM use was significant for P3 vs. P2 (OR $=0.78[0.64-0.96] P=0.02)$ and P4 vs. P3 (OR = $0.77[0.63-0.94] P=0.009)$. In parallel, the survival rate at ICU discharge increased significantly from $20 \%$ in 2011 to $26 \%$ in $2017(P=0.03)$, but the proportion of patients with good neurological outcome remained stable (19 to $23 \% ; P=0.76$ ) (Fig. 3).

In univariate analysis, TTM was significantly associated with a better neurological outcome with $\mathrm{OR}=2.71$ [2.30-3.19] and was associated with a better outcome after adjustment on baseline characteristics and year of arrest $(\operatorname{adjOR}=1.57$ [1.22-2.02]). Considering 2011 as the year of reference, a later onset of CA was not associated with a better outcome in univariate analysis $(P=$ 0.75) (Table 3). In addition, no interaction term between year of occurrence and parameters of interest (initial rhythm, bystander CPR performance, TTM) was significant $(P$ for interaction $>0.10)$.

Using segmented regression separating the study period into four separate sub-periods, the association between neurological outcome and periods was significant only for P4 vs. P3 (OR $=0.77[0.62-0.95] ; P=0.015)$ (see Figs. 2 and 3 ).

\section{Discussion}

Using the Paris-SDEC registry, which covers a large geographic area in France, we report that the overall proportion of post-cardiac arrest patients who received TTM decreased over years between 2011 and 2017. This decrease was observed in all patients' subgroups. In parallel, we observed that the activation of early resuscitation improved over time as reflected by an increase in the proportion of patients who received bystander CPR and a decrease in the proportion of patients with a long "no flow." Despite these improvements in early management, there was no significant change in neurological outcome over the study period.

Table 1 Characteristics of the study population according to targeted temperature management

\begin{tabular}{|c|c|c|c|}
\hline & No TTM $(n=1793)$ & $\operatorname{TTM}(n=1847)$ & $P$ \\
\hline Male, $n \%$ & $1169(65 \%)$ & $1318(71 \%)$ & $<0.001$ \\
\hline Age, \pm SD & $64 \pm 16$ & $61 \pm 15$ & $<0.001$ \\
\hline Home location, $n \%$ & $1186(66 \%)$ & $1017(55 \%)$ & $<0.001$ \\
\hline Witness, $n \%$ & $1569(87 \%)$ & $1697(92 \%)$ & $<0.001$ \\
\hline Bystander CPR, $n \%$ & $1142(63 \%)$ & $1195(65 \%)$ & $<0.001$ \\
\hline Shockable rhythm, $n \%$ & $592(33 \%)$ & $1065(58 \%)$ & $<0.001$ \\
\hline No-flow duration $>3 \min ^{*}, n \%$ & $666(37 \%)$ & $881(48 \%)$ & $<0.001$ \\
\hline Low-flow duration > $20 \mathrm{~min}^{*}, n \%$ & $588(33 \%)$ & $760(42 \%)$ & $<0.001$ \\
\hline Epinephrine use, $n \%$ & $1259(70 \%)$ & $1224(66 \%)$ & $<0.001$ \\
\hline First arterial $\mathrm{pH}, \pm \mathrm{SD}$ & $7.13 \pm 0.22$ & $7.22 \pm 0.15$ & $<0.001$ \\
\hline Post-resuscitation shock, $n \%$ & $863(48 \%)$ & $1253(68 \%)$ & $<0.001$ \\
\hline Early invasive coronary strategy, $n \%$ & 767 (43\%) & $1494(80 \%)$ & $<0.001$ \\
\hline Survival at ICU discharge, $n \%$ & $370(20 \%)$ & $689(37 \%)$ & $<0.001$ \\
\hline Good neurological prognosis at ICU discharge, $n \%$ & $273(15 \%)$ & $618(33 \%)$ & $<0.001$ \\
\hline
\end{tabular}

Values are expressed with proportion (\%), mean with standard deviation (SD) $C P R$ cardiopulmonary resuscitation

${ }^{*}$ Characteristics were dichotomized according to the median value 
Table 2 Baseline characteristics evolution over the years

\begin{tabular}{|c|c|c|c|c|c|c|c|c|c|}
\hline & All & 2011 & 2012 & 2013 & 2014 & 2015 & 2016 & 2017 & $P$ for trend \\
\hline$N$ & 3925 & 339 & 562 & 589 & 594 & 559 & 620 & 662 & \\
\hline Male, $n(\%)$ & $2682(70 \%)$ & $235(70 \%)$ & $386(68 \%)$ & $395(67 \%)$ & $401(67 \%)$ & 394 (70\%) & $442(71 \%)$ & $429(65 \%)$ & 0.63 \\
\hline Age, mean $\pm S D$ & $62 \pm 15$ & $62 \pm 14$ & $62 \pm 15$ & $62 \pm 15$ & $62 \pm 16$ & $61 \pm 15$ & $63 \pm 15$ & $62 \pm 16$ & 0.17 \\
\hline Home location, $n(\%)$ & $2365(58 \%)$ & $206(60 \%)$ & $341(60 \%)$ & $338(57 \%)$ & $342(57 \%)$ & $338(60 \%)$ & $392(63 \%)$ & $408(61 \%)$ & 0.17 \\
\hline Witnessed, $n(\%)$ & 3504 (90\%) & $320(94 \%)$ & $502(89 \%)$ & $516(88 \%)$ & $534(90 \%)$ & $489(87 \%)$ & $543(88 \%)$ & $600(90 \%)$ & 0.44 \\
\hline Bystander CPR, $n(\%)$ & $2525(66 \%)$ & $186(55 \%)$ & $310(55 \%)$ & $359(60 \%)$ & $384(65 \%)$ & $365(65 \%)$ & $437(70 \%)$ & $484(73 \%)$ & $<0.001$ \\
\hline Initial shockable rhythm, $n(\%)$ & $2215(50 \%)$ & $130(38 \%)$ & $256(45 \%)$ & $273(46 \%)$ & $298(50 \%)$ & $251(45 \%)$ & $289(46 \%)$ & $287(43 \%)$ & 0.26 \\
\hline No flow > $3 \mathrm{~min}^{*}, n(\%)$ & $1784(40 \%)$ & $179(53 \%)$ & $231(41 \%)$ & $236(40 \%)$ & $248(42 \%)$ & $232(41 \%)$ & $234(38 \%)$ & $253(38 \%)$ & $<0.001$ \\
\hline Low flow > $20 \mathrm{~min}^{*}, n(\%)$ & $1613(39 \%)$ & $121(36 \%)$ & $203(36 \%)$ & $207(35 \%)$ & $185(31 \%)$ & $198(35 \%)$ & $219(35 \%)$ & $264(40 \%)$ & 0.039 \\
\hline Use of epinephrine, $n$ (\%) & $2646(70 \%)$ & $245(72 \%)$ & $373(66 \%)$ & $401(68 \%)$ & $401(67 \%)$ & $393(70 \%)$ & $396(64 \%)$ & $437(66 \%)$ & 0.10 \\
\hline First arterial $\mathrm{pH}$, mean $\pm \mathrm{SD}$ & $7.2 \pm 0.2$ & $7.2 \pm 0.2$ & $7.2 \pm 0.2$ & $7.2 \pm 0.2$ & $7.2 \pm 0.2$ & $7.2 \pm 0.2$ & $7.2 \pm 0.2$ & $7.2 \pm 0.2$ & 0.49 \\
\hline Post-resuscitation shock, n (\%) & $2149(56 \%)$ & $253(74 \%)$ & $388(69 \%)$ & $338(57 \%)$ & $270(45 \%)$ & $305(54 \%)$ & $318(51 \%)$ & $277(42 \%)$ & $<0.001$ \\
\hline Early invasive coronary strategy, $n(\%)$ & $2349(60 \%)$ & $202(60 \%)$ & $336(60 \%)$ & $354(60 \%)$ & $367(62 \%)$ & $335(60 \%)$ & $388(63 \%)$ & $367(55 \%)$ & 0.13 \\
\hline Targeted temperature management, $n(\%)$ & $1847(47 \%)$ & $189(55 \%)$ & $321(57 \%)$ & $311(53 \%)$ & $275(46 \%)$ & $230(41 \%)$ & $278(45 \%)$ & $243(37 \%)$ & $<0.001$ \\
\hline Survival at ICU discharge, $n(\%)$ & $1106(26 \%)$ & $70(20 \%)$ & $153(27 \%)$ & $181(30 \%)$ & $188(32 \%)$ & $161(29 \%)$ & $176(28 \%)$ & $177(26 \%)$ & 0.03 \\
\hline Good neurological prognosis at ICU discharge, $n(\%)$ & $921(23 \%)$ & $63(19 \%)$ & $141(26 \%)$ & $160(28 \%)$ & $151(27 \%)$ & $135(26 \%)$ & $147(26 \%)$ & $124(23 \%)$ & 0.76 \\
\hline
\end{tabular}

Values are expressed with proportion (\%), mean with standard deviation (SD) $C P R$ cardiopulmonary resuscitation

${ }^{*}$ Characteristics were dichotomized according to the median value

Recent doubts regarding the efficacy of targeted temperature management (TTM) may have resulted in a loss of interest for this treatment in comatose cardiac arrest $(\mathrm{CA})$ patients. Indeed, following the publication of the TTM trial in 2013, several observational studies reported a change in ICU policies regarding temperature management after cardiac arrest. Up to one third of intensivists changed their temperature target from 33 to $36^{\circ} \mathrm{C}$ [6]. Using data from France (where therapeutic hypothermia is commonly used [19]), we report a clear fall in the use of TTM that was not associated with a change in neurological outcome over the same period. In a first approach, these findings do not suggest a detrimental effect of a lesser use of TTM on outcome in this population. However, this could have been concealed by a parallel improvement in the chain of survival that may have masked a negative effect of the decrease in the use of TTM. This interpretation is supported by the

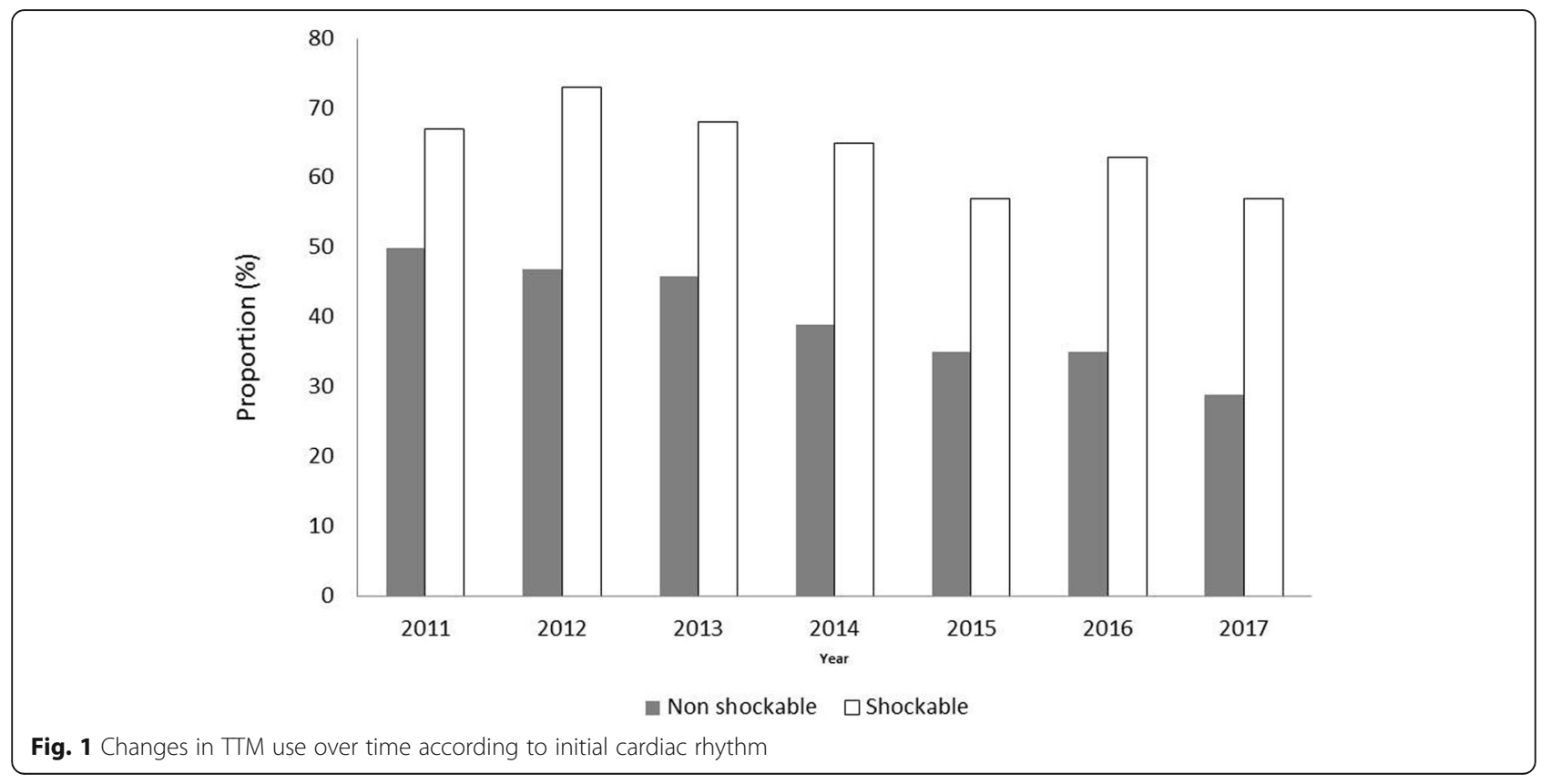


Table 3 Factors associated with good neurological prognosis at ICU discharge in uni- and multivariate analysis in multiple imputation cohort ( $N=3623$ patients)

\begin{tabular}{|c|c|c|c|c|}
\hline \multirow[t]{2}{*}{ Characteristics } & \multicolumn{2}{|l|}{ Univariate analysis } & \multicolumn{2}{|l|}{ Multivariate analysis } \\
\hline & Coefficient [95\%Cl] & $P$ value & Coefficient [95\%Cl] & $P$ value \\
\hline Male & 1.65 [1.39-1.97] & $<0.001$ & - & - \\
\hline Age & $0.97[0.96-0.98]$ & $<0.001$ & $0.96[0.95-0.97]$ & $<0.001$ \\
\hline Home location & $0.32[0.27-0.38]$ & $<0.001$ & $0.59[0.47-0.74]$ & $<0.001$ \\
\hline Bystander CPR & $2.62[2.16-3.19]$ & $<0.001$ & $1.65[1.19-2.28]$ & 0.003 \\
\hline Shockable rhythm & $9.70[8.04-11.70]$ & $<0.001$ & $2.96[2.29-3.93]$ & $<0.001$ \\
\hline No flow > $3 \mathrm{~min}^{*}$ & $0.38[0.32-0.45]$ & $<0.001$ & $0.48[0.36-0.64]$ & $<0.001$ \\
\hline Low flow > $20 \mathrm{~min}^{*}$ & $0.21[0.17-0.26]$ & $<0.001$ & $0.50[0.38-0.66]$ & $<0.001$ \\
\hline Epinephrine use* & $0.06[0.05-0.08]$ & $<0.001$ & $0.15[0.11-0.19]$ & $<0.001$ \\
\hline First arterial pH (by 0.1 unit) & $1.86[1.73-2.00]$ & $<0.001$ & $1.31[1.20-1.45]$ & $<0.001$ \\
\hline Post-resuscitation shock & $0.44[0.37-0.42]$ & $<0.001$ & $0.73[0.57-0.94]$ & 0.012 \\
\hline Early invasive coronary strategy & $8.16[6.50-10.25]$ & $<0.001$ & $3.24[2.37-4.43]$ & $<0.001$ \\
\hline Targeted temperature management & $2.71[2.30-3.19]$ & $<0.001$ & $1.57[1.22-2.02]$ & $<0.001$ \\
\hline Year of occurrence (2011 as reference) & $1.01[0.96-1.05]$ & 0.75 & - & - \\
\hline
\end{tabular}

CPR cardiopulmonary resuscitation

*Characteristics were dichotomized according to the median value

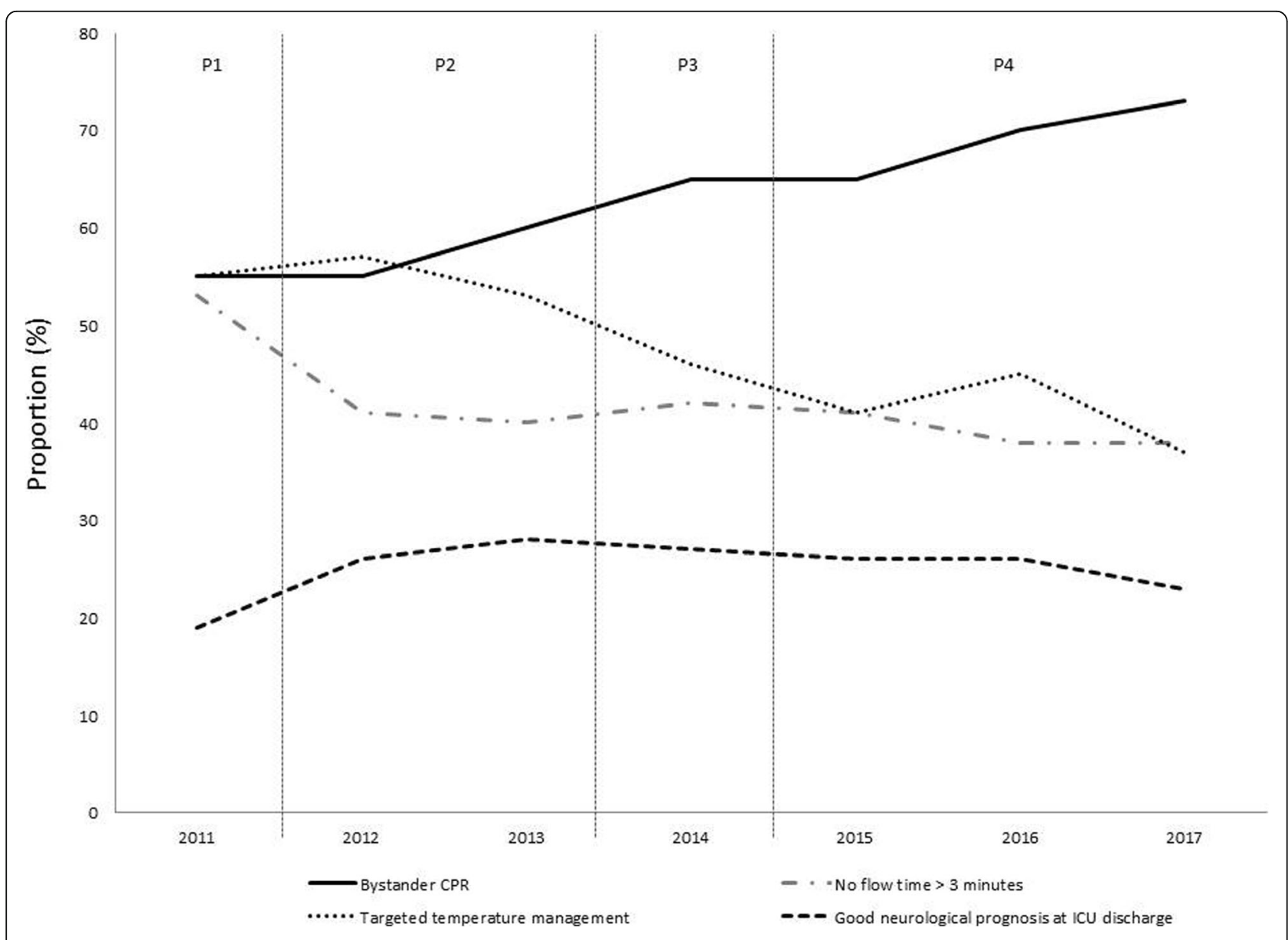

Fig. 2 Changes in characteristics and outcome according to periods of segmented regression analysis 


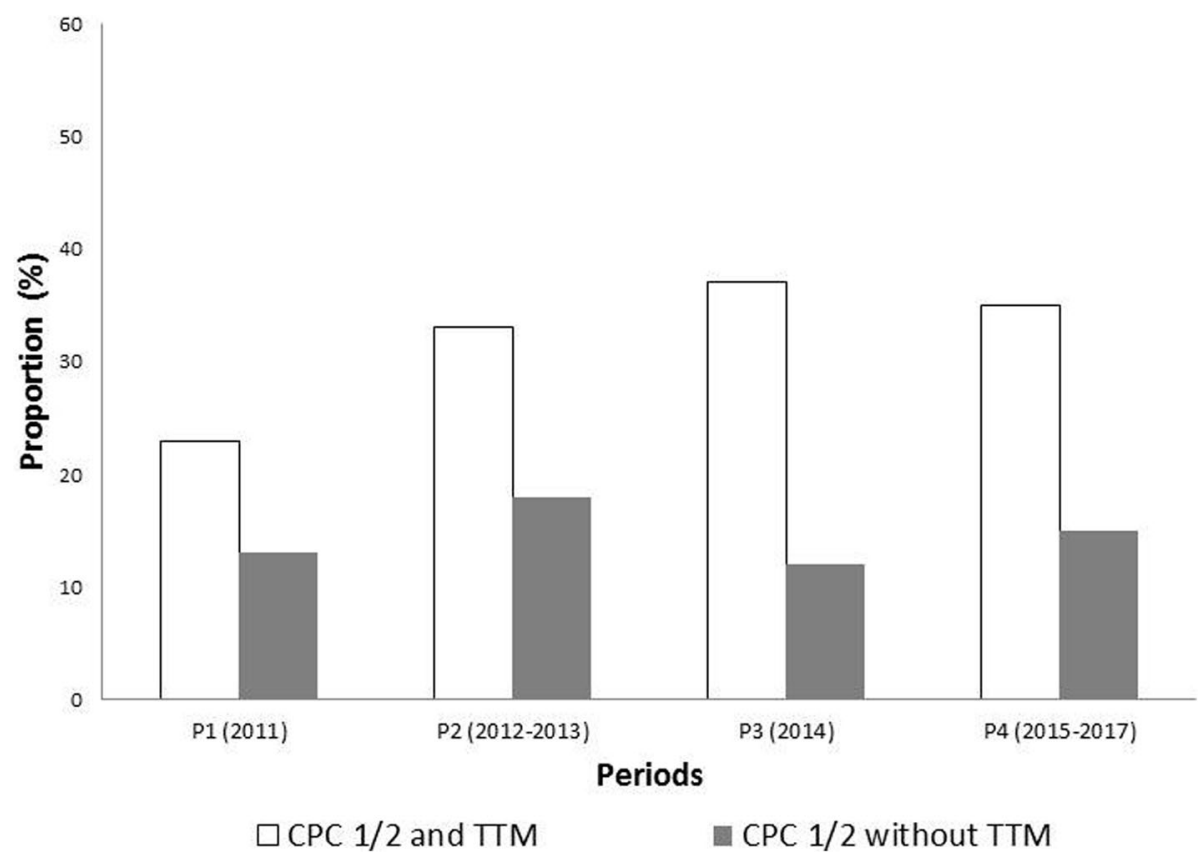

Fig. 3 Changes in neurological outcome according to periods of segmented regression analysis

protective effect of TTM that was observed in multivariable analysis and also by the segmented regression, which reveals a change in the association between neurological outcome and periods for the most recent years. On the whole, it is not possible to exclude that an improvement in outcome may have been observed if TTM had been more widely used. Of course, the design of the present study does not allow giving any firm conclusion regarding this debate.

The existence of an association between changes in TTM policies and outcome is debated as previous authors reported conflicting results [20, 21]. Our results are in accordance with those from a recent NorthAmerican study [8], which explored a quite similar population of post-cardiac arrest patients. On the opposite, our results are discordant with those from Salter et al. [5], who reported an association between the progressive switch from 33 to $36^{\circ} \mathrm{C}$ and an increase in both the proportion with fever in ICU and hospital mortality. However, there was no adjustment for major Utstein style confounders in the analysis. In the present study, we observed an increase over the years in bystander CPR and a decrease in no-flow duration, which are both major determinants of outcome [5]. We strongly believe that any further studies aiming to assess the relationship between post-cardiac arrest care and outcome should be adjusted on these major variables.

The loss of confidence in TTM may have been suspected to be deeper in non-shockable patients since the level of evidence regarding its efficacy was lower in this population, as compared with shockable patients [2]. However, a clear insight from the present study is that the lower adherence to TTM after CA was not driven by the cardiac rhythm at EMS presentation, since the decrease was observed in both shockable and nonshockable patients. In several retrospective studies, benefits from TTM at $33^{\circ} \mathrm{C}$ were more marked in patients with longer no-flow or low-flow times [22-24], but this result was not replicated in a post hoc analysis of the TTM trial [25]. In this context, it is unfortunate to observe that the fall in TTM use is also observed in shockable patients despite a strong recommendation in recent guidelines [16]. Regarding the subgroup of nonshockable patients, TTM use might increase in the next future due to the results of the HYPERION trial, which showed a significant improvement in neurological outcome at day 90 with TTM at $33^{\circ}$ as compared with normothermia [10].

The results of the present study suggest that the TTM trial may have been inaccurately interpreted as a negative study and may have discouraged the use of therapeutic hypothermia in post-cardiac patients. Even if the TTM trial was not designed to assess the efficacy of therapeutic hypothermia, the lack of difference in neurological outcome between patients managed at $33^{\circ}$ versus $36^{\circ}$ was probably considered as a negative signal regarding the efficacy of cooling. In the meantime, pivotal studies that established the efficacy of $\mathrm{TH}$ in post-cardiac arrest patients were challenged in several aspects (low number of 
patients, highly selected population, temperature strategy in the control group) $[26,27]$. Since cooling is a time-consuming treatment, this may explain the disaffection for this treatment. In this way, a particular attention should be paid to the results of the TTM-2 study, which is a large multicentric pragmatic trial comparing moderate hypothermia and normothermia in comatose cardiac patients [28].

Our results should be considered in the context of the study's limitations. We were unable to comment on potential changes in the quality of therapeutic hypothermia (e.g., time to target temperature and time in target temperature) that may also impact patients' outcome [29]. The higher proportion of patients with a short noflow duration is in sharp contrast to prior studies [30], but this proportion is close to what was reported in a non-selected north-American registry [31]. In addition, we decided to study the specific population of patients with a stable ROSC after hospital and ICU admission, a population in which the proportion of shockable patients is known to be high [32]. We were not able to identify the subset of patients who were managed with a strategy of "normothermia or avoiding fever" among those who did not receive TTM. However, each patient's chart was evaluated by a centralized monitor who checked the medical file for accuracy and competitiveness. Patients in the TTM group were younger, and even after multivariate adjustment, other unmeasured confounders may potentially explain their better outcome. Finally, only short-term outcome was considered, while long-term outcome would have been more adapted (such as 1month and 3-month outcome as recommended in COSCA guidelines [33]) and we cannot exclude than some non-survivors died of non-neurological cause [34].

\section{Conclusion}

Using a large regional registry of cardiac arrest, we report a progressive decrease in the use of TTM in postcardiac arrest patients over the recent years. In parallel, we observed that the activation of early resuscitation improved over time as reflected by an increase in the proportion of patients who received bystander-initiated resuscitation and a shorter "no flow." Despite these improvements in early management, there was no significant change in neurological outcome over the study period. Further research is required to explore the consequence of this decrease in the use of TTM.

\section{Supplementary information}

Supplementary information accompanies this paper at https://doi.org/10. 1186/s13054-019-2677-1.

Additional file 1. Patient flowchart

Additional file 2. Proportion of missing values in the study population.

\section{Abbreviations}

CA: Cardiac arrest; CPR: Cardiopulmonary resuscitation; ROSC: Return of spontaneous circulation; TTM: Targeted temperature management

\section{Acknowledgements}

Individual members of the Sudden Death Expertise Center Group to be searchable through their individual PubMed records:

Adnet F, AP-HP, Paris 13 University, Avicenne Hospital, Emergency Medical Services (SAMU) 93, Bobigny, FranceAgostinucci JM, AP-HP, Paris 13 University, Avicenne Hospital, Emergency Medical Services (SAMU) 93, Bobigny, France

Aissaoui-Balanant N, AP-HP, Georges Pompidou European Hospital, Medical Intensive Care Unit, Paris, France

Algalarrondo V, AP-HP, Antoine Beclere University Hospital, Department of Cardiology, Clamart, France

Alla F, French National Health Insurance (CNAMTS), Paris, France

Alonso C, Clinique Ambroise Paré, Department of Cardiology, Neuilly, France Amara W, Hospital Group of Montfermeil - Le Raincy, Department of

Cardiology, Montfermeil, France

Annane D, AP-HP, INSERM U1173 (Laboratory of Inflammation and Infection), University of Versailles - Saint Quentin en Yvelines, Raymond Poincare Hospital, General Intensive Care Unit, Garches, France

Antoine C, Biomedecine agency, Saint-Denis-la-Plaine, France

Aubry P, AP-HP, Bichat Hospital, Department of Cardiology, Paris, France Azoulay E, AP-HP, Paris Diderot Sorbonne University, Saint Louis Hospital, Medical Intensive Care Unit, Paris, France

Beganton F, INSERM U970 - PARCC, Paris, France

Benhamou D, AP-HP, Bicetre Hospital, Department of Anaesthesia and Intensive Care Medicine, Le Kremlin-Bicetre, France

Billon C, AP-HP, Georges Pompidou European Hospital, Department of Genetic, Paris, France

Bougouin W, INSERM U970 - PARCC, Paris, France

Boutet J, AP-HP, Raymond Poincare Hospital, Emergency Medical Services (SAMU) 92, Garches, France

Bruel C, Saint Joseph Hospital, Medical-Surgical Intensive Care Unit, Paris, France.

Bruneval P, AP-HP, Georges Pompidou European Hospital, Pathology Department, Paris, France

Cariou A, AP-HP, Cochin Hospital, Medical Intensive Care Unit, Paris, France Carli P, AP-HP, Paris Descartes University, Necker - Enfants Malades Hospital, Emergency Medical Services (SAMU) 75, Intensive Care Unit, Paris, France Casalino E, AP-HP, Emergency Medical Services (SAMU) 92, Clichy, France Cerf C, Foch Hospital, Intensive Care Unit, Suresnes, France

Chaib A, Andre Gregoire Hospital, Department of Cardiology, Montreuil, France Cholley B, AP-HP, Georges Pompidou European Hospital, Department of Anaesthesia and Surgical Intensive Care Medicine, Paris, France

Cohen Y, AP-HP, Avicenne Hospital, Medical-Surgical Intensive Care Unit, Bobigny, France

Combes A, AP-HP, Pitié-Salpetriere Hospital, Cardiology Institute (ICAN), Intensive Care Unit, Paris, France

Crahes M, AP-HP, Georges Pompidou European Hospital, Pathology Department, Paris, France

Da Silva D, Delafontaine Hospital, Intensive Care Unit, Saint-Denis, France Das V, Andre Gregoire Hospital, Medical-Surgical Intensive Care Unit, Montreuil, France

Demoule A, AP-HP, Pitie Salpetriere Hospital, Medical Intensive Care Unit and Respiratory Division, Paris, France

Denjoy I, AP-HP, Bichat Hospital, Department of Cardiology, Paris, France Deye N, AP-HP, Lariboisiere Hospital, Intensive Care Unit, Paris, France

Dhonneur G, AP-HP, Henri Mondor Hospital, Department of Anaesthesia and Surgical Intensive Care Medicine, Creteil, France

Diehl JL, AP-HP, Georges Pompidou European Hospital, Medical Intensive Care Unit, Paris, France

Dinanian S, AP-HP, Antoine Beclere Hospital, Department of Cardiology, Clamart, France

Domanski L, Brigade de Sapeurs Pompiers de Paris (BSPP), Paris, France Dreyfuss D, AP-HP, Louis Mourier Hospital, Intensive Care Unit, Colombes, France

Duboc D, AP-HP, Cochin Hospital, Department of Cardiology, Paris, France Dubois-Rande JL, AP-HP, Henri Mondor Hospital, Department of Cardiology, Creteil, France 
Dumas F, AP-HP, Cochin Hospital, Department of Emergency, Paris, France Empana JP, INSERM U970 - PARCC, Paris, France

Extramiana F, AP-HP, Bichat Hospital, Department of Cardiology, Paris, France Fartoukh M, AP-HP, Sorbonne University (Paris 6), Tenon Hospital, Intensive Care Unit, Paris, France

Fieux F, CHI Montfermeil, Intensive Care Unit, France

Gabbas M, French National Health Insurance (CNAMTS), Paris, France Gandjbakhch E, AP-HP, Pitie-Salpetriere Hospital, Cardiology Institute (ICAN), Department of Cardiology, Paris, France

Geri G, AP-HP, Ambroise Pare Hospital, Intensive Care Unit, BoulogneBillancourt, France

Guidet B, AP-HP, Sorbonne University (Pierre et Marie Curie University - Paris 6), Saint Antoine Hospital, Intensive Care Unit, Paris, France

Halimi F, Private Hospital of Parly 2, Department of Cardiology, Le Chesnay, France

Henry P, AP-HP, Sorbonne Paris Cite University (Paris Diderot University), Lariboisiere Hospital, Department of Cardiology, Paris, France

Hidden Lucet F, AP-HP, Pitie-Salpetriere Hospital, Cardiology Institute (ICAN), Department of Cardiology, Paris, France

Jabre P, INSERM U970 - PARCC, Emergency Medical Services (SAMU) 75,

Paris, France

Jacob L, AP-HP, Saint Louis Hospital, Department of Anaesthesia and Surgical Intensive Care Medicine, Paris, France

Joseph L, Bicetre Hospital, Transplant Coordination, Le Kremlin-Bicetre, France

Jost D, Brigade de Sapeurs Pompiers de Paris (BSPP), Paris, France

Jouven X, AP-HP, Georges Pompidou European Hospital, Department of Cardiology, Paris, France

Karam N, AP-HP, Georges Pompidou European Hospital, Department of Cardiology, Paris, France

Kassim H, INSERM U970 - PARCC, Paris, France

Lacotte J, Private Hospital Jacques Cartier, Department of Cardiology, Massy, France

Lahlou-Laforet K, AP-HP, Georges Pompidou European Hospital, Department of Psychiatry, Paris, France

Lamhaut L, AP-HP, Paris Descartes University, Necker - Enfants Malades Hospital, Emergency Medical Services (SAMU) 75, Intensive Care Unit, Paris, France Lanceleur A, Foch Hospital, Intensive Care Unit, Suresnes, France Langeron O, AP-HP, Pitie-Salpetriere Hospital, Department of Anaesthesia and Surgical Intensive Care Medicine, Paris, France

Lavergne T, AP-HP, Georges Pompidou European Hospital, Department of Cardiology, Paris, France

Lecarpentier E, AP-HP, Henri Mondor Hospital, Emergency Medical Services (SAMU) 94, Creteil, France

Leenhardt A, AP-HP, Bichat Hospital, Department of Cardiology, Paris, France Lellouche N, AP-HP, Henri Mondor Hospital, Department of Cardiology, Creteil, France

Lemiale V, AP-HP, Paris Diderot University, Saint Louis Hospital, Medical Intensive Care Unit, Paris, France

Lemoine F, Brigade de Sapeurs Pompiers de Paris (BSPP), Paris, France Linval F, AP-HP, Paris 13 University, Avicenne Hospital, Emergency Medical Services (SAMU) 93, Bobigny, France

Loeb T, AP-HP, Raymond Poincare Hospital, Emergency Medical Services (SAMU) 92, Garches, France

Ludes B, Institute of Legal Medicine, Paris Descartes University, Paris, France Luyt CE, AP-HP, Pitie-Salpetriere Hospital, Cardiology Institute (ICAN), Intensive Care Unit, Paris, France

Maltret A, AP-HP, Necker - Enfants Malades Hospital, Department of Pediatric Cardiology, Paris, France

Mansencal N, Ambroise Pare Hospital, Department of Cardiology, BoulogneBillancourt, France

Mansouri N, AP-HP, Henri Mondor Hospital, Emergency Medical Services

(SAMU) 94, Creteil, France

Marijon E, AP-HP, Georges Pompidou European Hospital, Department of Cardiology, Paris, France

Marty J, AP-HP, Henri Mondor Hospital, Emergency Medical Services (SAMU) 94, Creteil, France

Maury E, AP-HP, Sorbonne University (Pierre et Marie Curie University - Paris 6), Saint Antoine Hospital, Intensive Care Unit, Paris, France

Maxime V, AP-HP, Raymond Poincare Hospital, General Intensive Care Unit,

Garches, France
Megarbane B, AP-HP, Lariboisiere Hospital, Intensive Care Unit, Paris, France Mekontso-Dessap A, AP-HP, DHU A-TVB, CARMAS Research Group, Henri Mondor Hospital, Intensive Care Unit, Creteil, France

Mentec $\mathrm{H}$, Victor Dupouy Hospital, Intensive Care Unit, Argenteuil, France Mira JP, AP-HP, Cochin Hospital, Medical Intensive Care Unit, Paris, France Monnet X, AP-HP, Bicetre Hospital, Medical Intensive Care Unit, Le KremlinBicetre, France

Narayanan K, INSERM U970 - PARCC, Paris, France

Ngoyi N, AP-HP, Paris 7 University, Beaujon Hospital, Emergency Medical Services (SAMU) 92, Clichy, France

Perier MC, INSERM U970 - PARCC, Paris, France

Piot O, Centre Cardiologique du Nord, Department of Cardiology, SaintDenis, France

Pirracchio R, AP-HP, Georges Pompidou European Hospital, Intensive Care Unit, Paris, France

Plaisance P, Emergency Medical Services (SAMU) 75, Lariboisière SMUR, Paris, France

Plu I, AP-HP, Pitie-Salpetriere Hospital, Neuropathology Escourolle, Paris, France

Raux M, AP-HP, Pitié Salpétrière Hospital, Department of Anesthesiology and Critical Care, Paris, France

Revaux F, AP-HP, Henri Mondor Hospital, Emergency Medical Services (SAMU) 94, Creteil, France

Ricard JD, AP-HP, Louis Mourier Hospital, Intensive Care Unit, Colombes, France

Richard C, AP-HP, Bicetre Hospital, Medical Intensive Care Unit, Le KremlinBicetre, France

Riou B, AP-HP, Pitie-Salpetriere Hospital, Sorbonne University (Pierre et Marie Curie University - Paris 6), Department of Emergency Medicine and Surgery, Paris, France

Roussin F, AP-HP, Saint Louis Hospital, Department of Anaesthesia and Surgical Intensive Care Medicine, Paris, France

Santoli F, Robert Ballanger Hospital, Intensive Care Unit, Aulnay-sous-Bois, France

Schortgen F, Centre Hospitalier Intercommunal Créteil, Intensive Care Unit, Creteil, France

Sharifzadehgan A, AP-HP, Georges Pompidou European Hospital, Department of Cardiology, Paris, France

Sideris G, AP-HP, Sorbonne Paris Cite University (Paris Diderot University), Lariboisiere Hospital, Department of Cardiology, Paris, France

Spaulding C, AP-HP, Georges Pompidou European Hospital, Department of Cardiology, Paris, France

Teboul JL, AP-HP, Bicetre Hospital, Medical Intensive Care Unit, Le KremlinBicetre, France

Timsit JF, AP-HP, Bichat Hospital, Medical Intensive Care Unit, Paris, France Tourtier JP, Brigade de Sapeurs Pompiers de Paris (BSPP), Paris, France Tuppin P, French National Health Insurance (CNAMTS), Paris, France Ursat C, AP-HP, Raymond Poincare Hospital, Emergency Medical Services (SAMU) 92, Garches, France

Varenne O, AP-HP, Cochin Hospital, Department of Cardiology, Paris, France Vieillard-Baron A, AP-HP, Ambroise Pare Hospital, Intensive Care Unit, Boulogne-Billancourt, France

Voicu S, AP-HP, Lariboisiere Hospital, Intensive Care Unit, Paris, France Wahbi K, AP-HP, Cochin Hospital, Department of Cardiology, Paris, France Waldmann V, AP-HP, Georges Pompidou European Hospital, Department of Cardiology, Paris, France

\section{Take-home message}

Use of targeted temperature management after cardiac arrest declined over the years in both shockable and non-shockable patients. After adjustment for major confounders, this decline was not associated with a change in neurological outcome at ICU discharge.

\section{Tweet}

Use of \#TTM after \#OHCA declined over the years in both shockable and non-shockable patients. After adjustment, this decline was not associated with a change in neurological outcome at ICU discharge.

\section{Authors' contributions}

$J B L$ was responsible for the study concept and design; WB, NA, RC, SL, ND,

$L L, D J, E M, A V B$, and WJ were responsible for the acquisition of the data; $J B L$, 
$W B, A C$, and $F D$ were responsible for the analysis and interpretation of the data; JBL, $A C$, and FD were responsible for the drafting of the manuscript: $J B L, A C$, and FD were responsible for the interpretation of the data and critical revision of the manuscript for important intellectual content. All authors read and approved the final manuscript.

\section{Funding}

This study was funded solely by institutional and departmental sources.

\section{Availability of data and materials}

Data are available on reasonable request to the first and last authors and after approval by all authors of the manuscript.

\section{Ethics approval and consent to participate}

Appropriate review boards approved the investigation (CNIL approval 912309; CCTIRS approval 12336).

\section{Consent for publication}

Not applicable.

\section{Competing interests}

AC received fees for lectures from C.R. Bard (Murray Hill, NJ, USA). The other authors declare that they have no competing interests.

\section{Author details}

'Service de Medecine Intensive Reanimation, Centre Hospitalier Universitaire, 30 Boulevard Jean Monnet, 44093 Nantes Cedex 9, France. ${ }^{2}$ Université de Paris, INSERM, Paris Cardiovascular Research Centre, Paris, France. ${ }^{3}$ Paris Sudden Death Expertise Center, Paris, France. ${ }^{4}$ AfterROSC Network Group, Paris, France. ${ }^{5}$ Emergency Department, Cochin University Hospital, APHP, Paris, France. ${ }^{6}$ Medical Surgical Intensive Care Unit, Mignot Hospital, Le Chesnay, France. ${ }^{7}$ Medical Intensive Care Unit, European University Hospital, Paris, France. ${ }^{8}$ Medical Intensive Care Unit, Lariboisière University Hospital, Paris, France. ${ }^{9}$ SAMU de Paris, DAR Necker University Hospital-Assistance, Paris, France. ${ }^{10}$ Brigade des Sapeurs-Pompiers de Paris, Paris, France. ${ }^{11}$ Medical Intensive Care Unit, Ambroise Pare University Hospital, APHP, Boulogne-Billancourt, France. ${ }^{12}$ Medical Intensive Care Unit, Cochin University Hospital, APHP, Paris, France.

\section{Received: 29 August 2019 Accepted: 15 November 2019} Published online: 03 December 2019

\section{References}

1. Kragholm K, Wissenberg M, Mortensen RN, Hansen SM, Malta Hansen C, Thorsteinsson K, Rajan S, Lippert F, Folke F, Gislason G, et al. Bystander efforts and 1-year outcomes in out-of-hospital cardiac arrest. New England J Med. 2017;376(18):1737-47.

2. Dumas F, Grimaldi D, Zuber B, Fichet J, Charpentier J, Pene F, Vivien B, Varenne $\mathrm{O}$, Carli P, Jouven $\mathrm{X}$, et al. Is hypothermia after cardiac arrest effective in both shockable and nonshockable patients? Insights from a large registry. Circulation. 2011;123(8):877-86.

3. Nielsen N, Wetterslev J, Cronberg T, Erlinge D, Gasche Y, Hassager C, Horn J, Hovdenes J, Kjaergaard J, Kuiper M, et al. Targeted temperature management at 33 degrees $C$ versus 36 degrees $C$ after cardiac arrest. N Engl J Med. 2013;369(23):2197-206.

4. Nielsen N, Friberg H, Gluud C, Herlitz J, Wetterslev J. Hypothermia after cardiac arrest should be further evaluated--a systematic review of randomised trials with meta-analysis and trial sequential analysis. Int J Cardiol. 2011:151(3):333-41.

5. Salter R, Bailey M, Bellomo R, Eastwood G, Goodwin A, Nielsen N, Pilcher D, Nichol A, Saxena M, Shehabi $Y$, et al. Changes in temperature management of cardiac arrest patients following publication of the target temperature management trial. Crit Care Med. 2018:46(11):1722-30.

6. Deye $N$, Vincent $F$, Michel $P$, Ehrmann S, Silva D, Piagnerelli M, Kimmoun A, Hamzaoui O, Lacherade J-C, Jonghe B, et al. Changes in cardiac arrest patients' temperature management after the 2013 "TTM" trial: results from an international survey. Ann Intensive Care. 2016;6(1):1-9.

7. Bray JE, Stub D, Bloom JE, Segan L, Mitra B, Smith K, Finn J, Bernard S. Changing target temperature from 33 degrees $C$ to 36 degrees $C$ in the ICU management of out-of-hospital cardiac arrest: a before and after study. Resuscitation. 2017;113:39-43.
8. Bradley SM, Liu W, McNally B, et al. Temporal trends in the use of therapeutic hypothermia for out-of-hospital cardiac arrest. JAMA Netw Open. 2018;1(7):e184511.

9. Khera R, Humbert A, Leroux B, Nichol G, Kudenchuk P, Scales D, Baker A, Austin M, Newgard CD, Radecki R, et al. Hospital variation in the utilization and implementation of targeted temperature management in out-ofhospital cardiac arrest. Circulation. 2018;11(11):e004829.

10. Lascarrou J-B, Merdji H, Le Gouge A, Colin G, Grillet G, Girardie P, Coupez E, Dequin P-F, Cariou A, Boulain T, et al. Targeted temperature management for cardiac arrest with nonshockable rhythm. N Engl J Med. 2019. https:// doi.org/10.1056/NEJMoa1906661.

11. Bougouin W, Lamhaut L, Marijon E, Jost D, Dumas F, Deye N, Beganton F, Empana JP, Chazelle E, Cariou A, et al. Characteristics and prognosis of sudden cardiac death in Greater Paris: population-based approach from the Paris Sudden Death Expertise Center (Paris-SDEC). Intensive Care Med. 2014; 40(6):846-54.

12. Maupain C, Bougouin W, Lamhaut L, Deye N, Diehl JL, Geri G, Perier MC, Beganton F, Marijon E, Jouven X, et al. The CAHP (Cardiac Arrest Hospital Prognosis) score: a tool for risk stratification after out-of-hospital cardiac arrest. Eur Heart J. 2016;37(42):3222-8.

13. Bougouin W, Dumas F, Karam N, Maupain C, Marijon E, Lamhaut L, Jost D, Geri G, Beganton F, Varenne O, et al. Should we perform an immediate coronary angiogram in all patients after cardiac arrest?: insights from a large French registry. JACC Cardiovasc Interv. 2018;11(3):249-56.

14. Perkins GD, Jacobs IG, Nadkarni VM, Berg RA, Bhanji F, Biarent D, Bossaert LL, Brett SJ, Chamberlain D, de Caen AR, et al. Cardiac arrest and cardiopulmonary resuscitation outcome reports: update of the Utstein Resuscitation Registry Templates for Out-of-Hospital Cardiac Arrest: a statement for healthcare professionals from a task force of the International Liaison Committee on Resuscitation (American Heart Association, European Resuscitation Council, Australian and New Zealand Council on Resuscitation, Heart and Stroke Foundation of Canada, InterAmerican Heart Foundation, Resuscitation Council of Southern Africa, Resuscitation Council of Asia); and the American Heart Association Emergency Cardiovascular Care Committee and the Council on Cardiopulmonary, Critical Care, Perioperative and Resuscitation. Circulation. 2015:132(13):1286-1300.

15. Jennett B, Bond M. Assessment of outcome after severe brain damage: a practical scale. Lancet. 1975:305(7905):480-4.

16. Nolan JP, Soar J, Cariou A, Cronberg T, Moulaert VR, Deakin CD, Bottiger BW, Friberg $\mathrm{H}$, Sunde K, Sandroni C. European Resuscitation Council and European Society of Intensive Care Medicine Guidelines for Postresuscitation Care 2015: Section 5 of the European Resuscitation Council Guidelines for Resuscitation 2015. Resuscitation. 2015;95:202-22.

17. White IR, Royston P, Wood AM. Multiple imputation using chained equations: issues and guidance for practice. Stat Med. 2011;30(4):377-99.

18. Wagner AK, Soumerai SB, Zhang F, Ross-Degnan D. Segmented regression analysis of interrupted time series studies in medication use research. J Clin Pharm Ther. 2002;27(4):299-309.

19. Orban JC, Cattet $F$, Lefrant JY, Leone $M$, Jaber $S$, Constantin JM, Allaouchiche B, Ichai C. The practice of therapeutic hypothermia after cardiac arrest in France: a national survey. PLoS One. 2012;7(9):e45284.

20. Casamento A, Minson A, Radford S, Martensson J, Ridgeon E, Young P, Bellomo R. A comparison of therapeutic hypothermia and strict therapeutic normothermia after cardiac arrest. Resuscitation. 2016;106:83-8.

21. Arvidsson L, Lindgren S, Martinell L, Lundin S, Rylander C. Target temperature 34 vs. 36 degrees C after out-of-hospital cardiac arrest - a retrospective observational study. Acta anaesthesiologica Scandinavica. 2017:61(9):1176-83.

22. Testori C, Sterz F, Holzer M, Losert H, Arrich J, Herkner H, Krizanac D, Wallmuller C, Stratil P, Schober A, et al. The beneficial effect of mild therapeutic hypothermia depends on the time of complete circulatory standstill in patients with cardiac arrest. Resuscitation. 2012;83(5):596-601.

23. Kagawa E, Inoue I, Kawagoe T, Ishihara M, Shimatani Y, Kurisu S, Nakama Y, Dai K, Otani T, Ikenaga $\mathrm{H}$, et al. Who benefits most from mild therapeutic hypothermia in coronary intervention era? A retrospective and propensitymatched study. Critical Care (London, England). 2010;14(4):R155.

24. Drennan IR, Lin S, Thorpe KE, Morrison LJ. The effect of time to defibrillation and targeted temperature management on functional survival after out-ofhospital cardiac arrest. Resuscitation. 2014;85(11):1623-8.

25. Kjaergaard J, Nielsen N, Winther-Jensen M, Wanscher M, Pellis T, Kuiper M, Hartvig Thomsen J, Wetterslev J, Cronberg T, Bro-Jeppesen J, et al. Impact 
of time to return of spontaneous circulation on neuroprotective effect of targeted temperature management at 33 or 36 degrees in comatose survivors of out-of hospital cardiac arrest. Resuscitation. 2015;96:310-6.

26. Group HaCAS. Mild therapeutic hypothermia to improve the neurologic outcome after cardiac arrest. N Engl J Med. 2002;346(8):549-56.

27. Bernard SA, Gray TW, Buist MD, Jones BM, Silvester W, Gutteridge G, Smith K. Treatment of comatose survivors of out-of-hospital cardiac arrest with induced hypothermia. N Engl J Med. 2002;346(8):557-63.

28. Dankiewicz J, Cronberg T, Lilja G, Jakobsen JC, Bělohlávek J, Callaway C, Cariou A, Eastwood G, Erlinge D, Hovdenes J et al: Targeted hypothermia versus targeted normothermia after out-of-hospital cardiac arrest (TTM2). A randomized clinical trial - rationale and design. Am Heart J 2019.

29. Deye N, Cariou A, Girardie P, Pichon N, Megarbane B, Midez P, Tonnelier JM, Boulain T, Outin H, Delahaye A, et al. Endovascular versus external targeted temperature management for out-of-hospital cardiac arrest patients: a randomized controlled study. Circulation. 2015.

30. Wissenberg M, Lippert FK, Folke F, Weeke P, Hansen CM, Christensen EF, Jans H, Hansen PA, Lang-Jensen T, Olesen JB, et al. Association of national initiatives to improve cardiac arrest management with rates of bystander intervention and patient survival after out-of-hospital cardiac arrest. Jama. 2013;310(13):1377-84.

31. van Diepen S, Girotra S, Abella BS, Becker LB, Bobrow BJ, Chan PS, Fahrenbruch C, Granger CB, Jollis JG, McNally B et al: Multistate 5-year initiative to improve care for out-of-hospital cardiac arrest: primary results from the HeartRescue Project. J Am Heart Assoc. 2017;6(9).

32. Chocron R, Bougouin W, Beganton F, Juvin P, Loeb T, Adnet F, Lecarpentier E, Lamhaut L, Jost D, Marijon E, et al. Are characteristics of hospitals associated with outcome after cardiac arrest? Insights from the Great Paris registry. Resuscitation. 2017;118:63-9.

33. Haywood K, Whitehead L, Nadkarni VM, Achana F, Beesems S, Böttiger BW Brooks A, Castrén M, Ong MEH, Hazinski MF, et al. COSCA (core outcome set for cardiac arrest) in adults: an advisory statement from the international liaison committee on resuscitation. Resuscitation. 2018;127:147-63.

34. Taccone FS, Horn J, Storm C, Cariou A, Sandroni C, Friberg H, Hoedemaekers CA, Oddo M. Death after awakening from post-anoxic coma: the "Best CPC" project. Crit Care. 2019;23(1):107.

\section{Publisher's Note}

Springer Nature remains neutral with regard to jurisdictional claims in published maps and institutional affiliations.

Ready to submit your research? Choose BMC and benefit from:

- fast, convenient online submission

- thorough peer review by experienced researchers in your field

- rapid publication on acceptance

- support for research data, including large and complex data types

- gold Open Access which fosters wider collaboration and increased citations

- maximum visibility for your research: over $100 \mathrm{M}$ website views per year

At $\mathrm{BMC}$, research is always in progress.

Learn more biomedcentral.com/submissions 